\title{
Exotic lagomorph may influence eagle abundances and breeding spatial aggregations: a field study and meta- analysis on the nearest neighbor distance
}

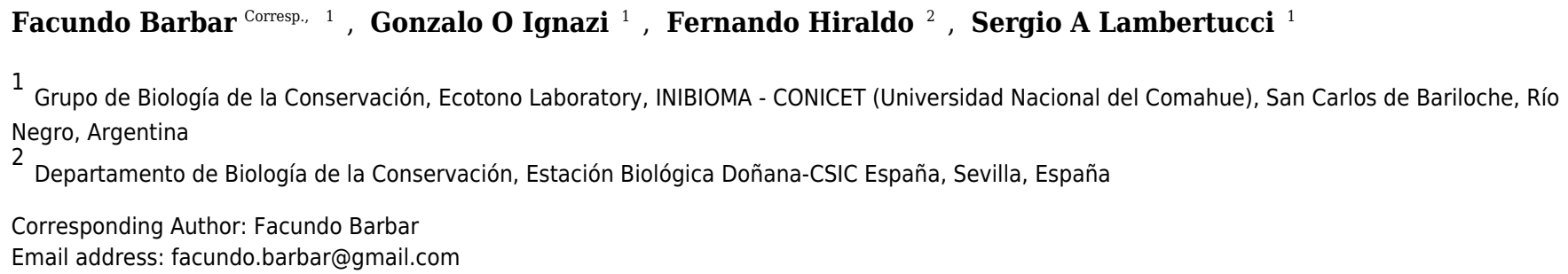

The introduction of alien species could be changing the food source composition, ultimately restructuring demography and spatial distribution of native communities. In Argentine Patagonia, the exotic European hare has one of the highest numbers recorded worldwide and is now a widely consumed prey for many predators. We examine the potential relationship between abundance of this relatively new prey and the abundance and breeding spacing of one of its main consumers, the Black-chested Buzzard-Eagle (Geranoaetus melanoleucus). First we analyze the abundances of individuals of a raptor guild in relation to hare abundances through a correspondence analysis. We then estimated the Nearest Neighbor Distance (NND) of the Black-chested Buzzard-eagle abundances in the two areas with high hare abundances. Finally, we performed a metaregression between the NND and the body masses of Accipitridae raptors, to evaluate if Black-chested Buzzard-eagle NND deviates from the expected accordingly to their mass. We found that eagles abundances were highly associated with hare abundances, more than any other raptor species in the study area. Their NND deviate from the value expected, which was significantly lower than expected for a raptor species of this size in two areas with high hare abundances. Our results support the hypothesis that high local abundance of prey leads to a reduction of the breeding spacing of its main predator, which could be potentially altering other interspecific interactions, and thus the entire community. 


\section{Title}

2 Exotic lagomorph may influence eagle abundances and breeding spatial aggregations: a field

3 study and meta-analysis on the nearest neighbor distance

\section{Authors}

5 Facundo Barbar ${ }^{1}$, Gonzalo O. Ignazi ${ }^{1}$, Fernando Hiraldo ${ }^{2}$, Sergio A. Lambertucci ${ }^{1}$

6 Corresponding author

7 Dr. Facundo Barbar, facundo.barbar@gmail.com.

\section{Authors' affiliation}

$9 \quad{ }^{1}$ Grupo de Investigación en Biología de la Conservación, Ecotono Laboratory, INIBIOMA -

10 CONICET (Universidad Nacional del Comahue), San Carlos de Bariloche, Río Negro,

11 Argentina.

12 2Departamento de Biología de la Conservación - Estación biológica Doñana, CSIC España,

13 Sevilla, España. 


\section{Abstract}

The introduction of alien species could be changing the food source composition, ultimately restructuring demography and spatial distribution of native communities. In Argentine Patagonia, the exotic European hare has one of the highest numbers recorded worldwide and is now a widely consumed prey for many predators. We examine the potential relationship between abundance of this relatively new prey and the abundance and breeding spacing of one of its main consumers, the Black-chested Buzzard-Eagle (Geranoaetus melanoleucus). First we analyze the abundances of individuals of a raptor guild in relation to hare abundances through a correspondence analysis. We then estimated the Nearest Neighbor Distance (NND) of the Blackchested Buzzard-eagle abundances in the two areas with high hare abundances. Finally, we performed a meta-regression between the NND and the body masses of Accipitridae raptors, to evaluate if Black-chested Buzzard-eagle NND deviates from the expected accordingly to their mass. We found that eagles abundances were highly associated with hare abundances, more than any other raptor species in the study area. Their NND deviate from the value expected, which was significantly lower than expected for a raptor species of this size in two areas with high hare abundances. Our results support the hypothesis that high local abundance of prey leads to a reduction of the breeding spacing of its main predator, which could be potentially altering other

31 interspecific interactions, and thus the entire community.

\section{Short title}

33 Exotic prey effects on eagles abundances 


\section{Introduction}

The spatial distribution of a species is determined by extrinsic and intrinsic factors.

Resource availability is the main extrinsic factor that may influence spatial distribution of organisms (Guisan \& Zimmermann, 2000; Guisan \& Thuiller, 2005). Changes in food sources could be modifying consumers' spatial distribution. Ecosystems are composed of different species that consume resources that are naturally limited (Chase \& Leibold, 2003). Within a given trophic level, interspecific and intraspecific interactions emerge in order to use these resources. These include agonistic interactions as direct competition and spatial exclusion and intraguild predation (Amarasekare, 2003; Sergio \& Hiraldo, 2008) as well as resource partitioning that favors species' coexistence (Martin \& others, 1996; McDonald, 2002; Griffin et al., 2008). At the individual level, the exclusion of conspecifics leads to territoriality, eventually reaching a spatial configuration that maximizes the number of territories in a given area as a function of resource availability (MacLean \& Seastedt, 1979; Schoener, 1983).

One of the main intrinsic factors limiting the spatial distribution of species is animals' body mass, as larger species require more energy to fulfill their energetic metabolic requirements (Damuth, 1981; Peters, 1986; White et al., 2007). In any guild (e.g., carnivores, raptors), the difference in body mass of the various species, is the main factor driving resource partitioning (Aljetlawi, Sparrevik \& Leonardsson, 2004; Brose, 2010), as consumers select prey that provides a positive energetic balance between food intake and handling time (Brose et al., 2006; Allhoff \& Drossel, 2016). This process of prey selection is directly linked to competing species coexistence (Loreau \& Hector, 2001; Amarasekare, 2002). On the other hand, this energetic constraint also implies that larger species may require larger territories to provide enough 
57 resources, therefore spacing their territories more widely than smaller species (Schoener, 1968;

58 Peery, 2000).

59

60 In the current global change scenario, humans are responsible for altering the ecosystems

61 in several ways and these changes are occurring in an accelerated way (Barnosky et al., 2012).

62 The introduction of species is among of the main factors of global change, which is not only

63 homogenizing biodiversity at a global scale but also has the potential of altering energy fluxes

64 (McKinney \& Lockwood, 1999; Newsome et al., 2015). The introduction of exotic species may

65 profoundly impact the relative abundance of native species and therefore community structure

66 (Vitousek, 1990; Vitousek et al., 1997; Tilman, 1999; Newsome et al., 2015), which may be in

67 favor of some native species over others, improving their population parameters. However, this

68 change in structure can lead to unbalanced ecological situations (e.g.: Tablado et al. 2010;

69 Speziale \& Lambertucci 2013).

Patagonia is one such region, at the southern tip of South America, to have suffered multiple species introductions (Rodríguez, 2001). One of the most conspicuous invaders has been the European hare (Lepus europaeus) which reached the region in the early 1900's (Grigera \& Rapoport, 1983). European hare had no other similar species in the region and became extremely abundant in number over a short period of time (Bonino, Cossíos \& Menegheti, 2010). As such, this introduced species may potentially alter energy fluxes, trophic interactions and

77 indirectly change community structure (Simberloff \& Von Holle, 1999; Simberloff et al., 2013). In fact, there is evidence that many predators in Patagonia have already shifted their diets to 
include this new and abundant source of food (Monserrat, Funes \& Novaro, 2005; Zanón Martínez et al., 2012; Barbar, Hiraldo \& Lambertucci, 2016).

$$
\text { Top predators that depend upon scarce resources are adequate to explore the resource }
$$
availability-territory size relationship, as their territories cover greater areas than herbivorous species (Schoener, 1968) and any change can be easily quantified with simple metrics such as the Nearest Neighbor Distance (NND, Clark \& Evans, 1954). This includes raptor species that generally behave as central place foragers and whose territory sizes are determined by resource abundance (Sonerud, 1992; Newton, 2010). Their fidelity to nesting areas means that the geographical distance between breeding sites can be used to quantify the relationship between resource availability and territory size and location.

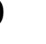

2
hare) may influence the raptor guild at the higher tropic level, paying particular attention to the Black-chested Buzzard-eagle (Geranoaetus melanoleucus; hereafter BCB eagle), which is the species that consumes it the most (Barbar, Hiraldo \& Lambertucci, 2016). For this we first quantified and compared the abundance of different raptor species to the abundance of hares in Northwestern Patagonia. We then, determined the Nearest Neighbor Distance (NND) for the BCB eagle in an area of high exotic hare population density. Finally, we compared our NND results with similar species of the Accipitridae family, conducting a meta-analysis on the NND reported for these species worldwide. Our hypothesis is that the abundance of BCB eagles and the spacing of their territories will be strongly influenced by the abundance of its principal prey, the exotic European hare. We predict that 1) the abundance of BCB eagles will be more closely 
102 linked to the abundance of hares, than will the other raptor species in the guild, and 2) that the

103 distance between $\mathrm{BCB}$ eagle territories will be smaller than expected for an eagle this size where

104 there is a high abundance of its main prey.

105

\section{Methods}

107 Studyarea

Fieldwork was conducted in northwest Patagonia, Argentina; in an area of approximately $15,000 \mathrm{~km}^{2}$ (Fig. 1). The climate is temperate-cold (annual mean $6^{\circ} \mathrm{C}$ ), with a marked west-toeast precipitation gradient, varying from $1000 \mathrm{~mm}$ to $400 \mathrm{~mm}$ annually (Paruelo et al., 1998).

111 The predominant habitat is an open herbaceous steppe (Festuca pallescens, Stipa speciosa), with

112 scattered srhubs (Mulinum spinosum) and with a frequent distribution of ecotonal forest

113 ingresions (Austrocedrus chilensis, Maytenus boaria, Cabrera, 1976). The region is comprised of

114 undulating hills and frequent rock outcrops, used by the raptors as roosting and nesting sites

115 (Coronato et al., 2008; Lambertucci \& Ruggiero, 2016). The presence of rock cliffs, shrubs and

116 trees are fairly evenly distributed on the entire study area, ensuring that all species studied have

117 plenty of choices at the time of placing their territories and nests. Field work permits for this

118 study were granted by the National Park Administration, Argentina (project 1360) and Ministry

119 of Territorial Development, General Direction of Fauna Resources.

\section{Study species}

122 In the Patagonian raptor guild, the most abundant species are two facultative scavengers 123 and three hunters. The Southern crested caracara (Caracara plancus) and the Chimango caracara 124 (Milvago chimango) are medium sized scavenging raptors that consume European hare mainly as 
125 carrion (Travaini et al., 1998). From the hunting raptors, the American kestrel (Falco sparverius,

$126 \sim 125$ g.), a small falcon, is too small to hunt or scavenge on hares, and the medium sized Red-

127 backed hawk (Geranoaetus polyosoma, $\sim 950$ g.) predates only on young hares, contributing to <

$12810 \%$ of their diet (Monserrat, Funes \& Novaro, 2005; Travaini, Santillán \& Zapata, 2012).

129 Whereas the BCB eagle (G. melanoleucus, $\sim 2450$ g.) commonly predates on the hare, consuming

130 between 15 to $90 \%$ of its diet (Iriarte, Franklin \& Johnson, 1990; Hiraldo et al., 1995;

131 Bustamante et al., 1997; Trejo, Kun \& Seijas, 2006).

132

The BCB eagle is a large Accipitrid that inhabits a diversity of open habitats across South America, from Venezuela to Tierra del Fuego (Ferguson-Lees \& Christie, 2001). It nests mainly in cliffs and rocky outcrops, although it can also use other substrates like trees, bushes and even structures along power-lines including telegraph poles (Jiménez \& Jaksić, 1989; Travaini et al., 1994; Hiraldo et al., 1995; Pavez, 2001; Saggese \& De Lucca, 2001; Ignazi, 2015). Adult BCB eagles exhibit strong territoriality and nest site fidelity throughout the years (Saggese et al. in press). Only juveniles are known to congregate in roosting places when a high resource aggregation exists (Bustamante et al. 1997; López, Grande \& Orozco-Valor, 2017). The breeding season in Patagonia extends from September to February, during the austral spring/summer (Hiraldo et al., 1995; Bustamante et al., 1997; Saggese \& De Lucca, 2001). It is considered to be a generalist species that feeds on small to medium sized mammals, birds, reptiles, carrion and arthropods (Hiraldo et al., 1995; Bustamante et al., 1997; Galende \& Trejo, 2003; Trejo, Kun \& 145 Seijas, 2006). 

covering 1000 linear kilometers (Fig. 1) each year, evenly distributed (i.e. whole transects were completed once each season). There, we counted the abundance of each of the five raptor species as well as the abundance of hare. Raptors were surveyed from a car driving at an average speed of $40 \mathrm{~km} / \mathrm{h}$, and during morning hours when they are more active and the probability to observe them is high (from 1 hour after sunrise to 12:00 h) and hare surveys were conducted at night

154 (from sunset to $2 \mathrm{am}$ ) with a spotlight checking both sides of the road (to a maximum distance of $50 \mathrm{~m}$ ), at a constant speed of $8 \mathrm{~km} / \mathrm{h}$. The difference in schedule being designed to maximize detectability associated with animal activities. For each observation we registered GPS location, species, number of individuals and perpendicular distance to the road. We later calculated species abundances per unit area in 13 a priori traced sections of the whole transect (Fig. 1). We did not find significant differences in counts between years, allowing us to pool data by site and using year as repetition. We conducted density analyses with the "Rdistance" package in Rstatistical software (R Development Core Team, 2012; McDonald, Nielson \& Carlisle, 2015). As abundances could be influenced by several factors, we first test if environmental variables, abundance of the primary prey or abundances of other raptors had an effect on the abundances of our focus species (the BCB eagle). For this we fit a GLM with the abundances of BCB eagles by site as the response variable and hare and other raptors abundances, year, nest availability (in three categories: low, medium, high) and dominant habitat (in three categories: steppe, shrub,

167 forest) as explanatory variables. We performed this analysis with "Ime4" package in R-statistical software (R Development Core Team 2012; Bates et al., 2014). We then performed a site. For this we organized a matrix with all 6 species (columns) and the 13 transect per year 
171 (rows), where each cell contained the density, previously calculated from counts in transects. For

172 this analysis we used the "vegan" package in R-statistical software (R Development Core Team,

173 2012; Oksanen, 2017).

174

Nearest neighbor distance

During the breeding seasons of 2012-13, in the austral late spring and summer, we

177 thoroughly searched 2 areas (of approximately $2000 \mathrm{~km}^{2}$ and $5000 \mathrm{~km}^{2}$, Fig. 1) to find active

BCB eagles nests. These areas were selected based on previous qualitative assessments showing

low degree of human disturbances (which may affect raptor distribution; Barbar et al. 2015), a

high abundance of eagles, hares and availability of cliffs (their most used nesting substrate,

181

182 Hijmans, 2016; Bivand et al., 2017).

192 193 2
Hiraldo et al., 1995). The two areas were selected because of their homogenous and abundant presence of potential nesting sites. There, the distances between cliff-shelves, trees and other nesting substrates are small enough to consider these sites as a non-limiting resource for the $\mathrm{BCB}$ eagles breeding pairs. Active nests were found either by direct observation (conspicuous stick structure of 1-2 m diameter in rock cliffs) or by observing couples behaviors around nesting areas (as they are highly territorial and spend most of the time in the vicinity). We confirmed that each nest was active when BCB eagles were building (or repairing it), showing incubation behavior or there was a fledgling at the nest. For each georeferenced nest site we calculated the NND applying the nearest neighbor algorithm using "geosphere", "rgeos" and "maptools" packages in R-statistical software (R Development Core Team, 2012; Bivand \& Rundel, 2014; 

in relation with their body mass we compared our results with other similar species through a bibliographic search of studies disclosing NND worldwide and a meta-regression. We focused our search on species similar to the BCB eagles (i.e., raptors from the family Accipitridae inhabiting open areas) in order to reduce additional extrinsic variations in the NND measures. We then excluded endangered species (e.g., Aquila adalberti), as their reduced populations would not represent their true comparable NNDs. Later, we excluded gregarious foragers and communal breeder species (e.g., Vultures, Gyps spp.), as their NNDs would not reflect their spatial accommodation regarding to food resources. We also excluded specialist foragers (e.g., Fish-eagles, Haliaeetus spp.), as their NNDs would be conditioned to their not randomly distributed resources, (for instance fish in certain rivers; Newton, 2010), while BCB eagles main prey is considered to be randomly distributed across landscapes in our study area (Bustamante et al., 1997). We ran a preliminary literature search using Scopus and Google Scholar with the key words "nearest neighbor distance", "nearest nest distance" and "NND" paired with the common names of the raptors "eagle" and "hawk". Then, to comprehensively complete our search, we used the same first terms of the search, paired with the name of each raptor species previously selected from Accipitridae family (e.g. "NND” AND “Aquila verreauxii”). All searches were performed by Facundo Barbar and reviewed by the other authors. From each study found we extracted the name of the first author and its year of publication (combined to form a study ID), as well as the raptor species, NND metric, its standard deviation (SD) and the number of nests used to calculate the NND (n). 
With this data we first performed an individual meta-analysis for each species using a

217 random-effects model, a method used to estimate the effect size of the entire population (Hunter \& Schmidt, 2000). In this way we obtained an outcome measure (hereafter $\mathrm{NND}_{\mathrm{avg}}$ ) for each

219 species depending on their NND, SD and n (Supporting information S1). We used this approach as preliminary exploration of the data showed high variability between studies ( $I^{2}$ always exceeding 90\%). This statistic estimates if the variability is due to heterogeneity between studies $\left(I^{2}>75 \%\right)$ or due to sampling variability within each study $\left(I^{2}<30 \%\right)$ (Higgins \& Thompson, 2002). Thus, analyzed as a whole, heterogeneity would be masking the actual effects and giving

unrealistic average values for each species. With the $\mathrm{NND}_{\text {avg }}$ outcome for each species we perform a meta-regression with a fixed-effects model (used to estimate the effect size among the sampled studies, Hunter \& Schmidt, 2000), using the species specific $\mathrm{NND}_{\text {avg }}$ as the dependent variable and the average weight of each species as the independent variable. We scaled the weights by exp -0.75 to account for the nonlinear change in metabolic rate (Damuth, 1981, 2007), which has been used for raptor species and proved to follow this nonlinear relationship (Palmqvist et al., 1996). For all these calculations we used the "metafor" package on R-statistical software (Viechtbauer, 2010; R Development Core Team, 2012).

\section{Results}

Raptor and hare densities

We found that the only significant variable (with a p-value threshold $<0.05$ ) affecting eagles abundances was the abundance of hares $(\beta=0.038 \pm 0.012 ; \mathrm{p}=0.047)$, while nest availability and the dominant habitat did not have any significant effect on its abundances

$238(\beta=0.079 \pm 0.216, \mathrm{p}=0.719 ; \beta=0.263 \pm 0.177, \mathrm{p}=0.149$, respectively $)$. The abundances of other 
239 raptor species did not have any significant effect on the abundance of BCB eagles; the estimates

240 were: $G$. polyosoma $(\beta=-0.086 \pm 0.185), C$. plancus $(\beta=0.083 \pm 0.090)$, M. chimango $(\beta=0.042$

$241 \pm 0.067)$ and $F$. sparverius $(\beta=0.128 \pm 0.081)$, all with $p$-values $>0.1$. Correspondence analysis

242 showed in the first two axes that the abundance of $G$. melanoleucus was closely linked to that of

243 the hare, while for other species the relationship was weaker (total explained inertia of 81.03\%;

244 Fig. 2). The abundances of the two facultative scavengers, C. plancus and M. chimango, were

245 similar to each other at all sites. On the other hand, the most dissimilar species was $G$.

246 polyosoma, which although did not present extremely low abundances (average density of 0.16

247 ind. $/ \mathrm{km}^{2}$ ) tended to be negatively linked to the abundance of hares and BCB eagles (Fig. 2). In

248 the two areas where we later actively searched for BCB eagle nests, hare densities were high.

249 Hare density in the northern area was 202.09 ind. $/ \mathrm{km}^{2}( \pm 25.26)$, while in the southern area was

$250249.25 \mathrm{ind} . / \mathrm{km}^{2}( \pm 22.65)$. Moreover, BCB eagle density mirrored those abundances with a mean

251 density of $0.71 \mathrm{ind} . / \mathrm{km}^{2}( \pm 0.18)$ in the north and $0.83 \mathrm{ind} . / \mathrm{km}^{2}( \pm 0.27)$ in the south.

252

253 Nearest neighbor

254 We found a total of 55 active nests within the two areas that were intensively searched. In

255 the northern area, we found 13 nests in the $2000 \mathrm{~km}^{2}$ covered, while in the southern area we

256 found 42 nests for the $5000 \mathrm{~km}^{2}$ scoped (Fig. 1). NND calculations ( $\mathrm{m} \pm \mathrm{SD}$ ) were $3797 \mathrm{~m}$

257 ( \pm 2477$)$ for the northern region and $3723 \mathrm{~m}( \pm 2594)$ for the southern area.

258

259

Body mass and NND relationships in raptors

We found 77 studies reporting NND for 13 species meeting our criteria obtaining a total

261 of 130 NND measures (Supporting information S1). We found a positive relationship between 
262 the Weight ${ }^{(-0.75)}$ and $\mathrm{NND}_{\text {avg }}($ Estimate $=-1087044 \pm 224387, \mathrm{p}<0.0001)$ in the meta-regression

$263\left(\mathrm{r}^{2}=67.96 \% ; I^{2}=95.77 \%\right.$; Fig. 3). Of all species included in the meta-regression, only three

264 had $\mathrm{NND}_{\text {avg }}$ measures that deviated significantly from the NND expected value. Aquila

265 chrysaetos presented higher values $\left(\mathrm{NND}_{\mathrm{avg}}=8242 \mathrm{~m} . v \mathrm{~s} . \mathrm{NND}\right.$ estimated $\left.=6013 \mathrm{~m}\right)$, while

266 Clanga pomarina $\left(\mathrm{NND}_{\mathrm{avg}}=2147 \mathrm{~m} . v \mathrm{~s} . \mathrm{NND}\right.$ estimated $\left.=3662 \mathrm{~m}\right)$ and our focus species $G$.

267 melanoleucus presented lower values $\left(\mathrm{NND}_{\mathrm{avg}}=4838 \mathrm{~m}\right.$ vs. NND estimated=6013m; Fig. 3)

268 indicating that in our study area, BCB eagles tended to reduce their distances between nesting 269 areas.

270

271

\section{Discussion}

In this study we found one of the highest abundances recorded for an eagle of more than

2 kg (e.g., Pedrini \& Sergio, 2001; Newton, 2010). Furthermore, eagle density was also reflected

in their nest spacing, since they have lower NND values than expected for raptors of this size.

We propose that these results can be explained by the extremely high abundances of the main

food source for the BCB eagle, the exotic European hare. In our study area hares reached one of the highest abundances recorded for this species (up to 249 ind. $/ \mathrm{km}^{2}$ ), only matched by the abundances recorded inside a fenced airfield in France, an area with no known predators (240 ind./km²; Flux \& Angermann, 1990). Thus, our results highlight how an introduced and abundant food source may modify spatial distribution and abundance of a top predator, even when the

281 introduction is relatively recent (during the last century).

The fact that from the raptor guild of Patagonia BCB eagle was the species most closely

284 linked to the high abundances of this new exotic food resource, may be related to the fact that 
285 this species is the only one, in the studied raptors guild, capable of hunting hares of all age

286 classes (Hiraldo et al., 1995; Bustamante et al., 1997). This is something which could be a

287 challenge for the two facultative species (C. plancus and M. chimango) that depend mostly on

288 carrion only, scavenging on hares (Travaini et al., 1998). Therefore, their abundance will depend

289 on other environmental and anthropogenic factors that increase the density of carrion and waste,

290 such as the presence of settlements (which produce resources as house wastes) or high traffic

291 roads (producing high rates of road kills) (Lambertucci et al., 2009; Barbar et al., 2015). As

292 expected the abundance of the smallest raptor (F. sparverius) did not show any relationship with

293 hare abundance, but surprisingly, within the same areas they were less abundant than the BCB

294 eagles. This could indicate that hare presence is enough to override the theoretical energetic

295 constraint for larger species, providing them with enough resources to become more abundant

296 that smaller ones (Peters, 1986). Finally, the Red-backed hawk (G. polyosoma) was negatively

297 related to the abundances of both hares and eagles. Their similar food habits and nesting sites

298 make the Red-backed hawk and the BCB eagle direct competitors (Schlatter, Yáñez \& Jaksić,

299 1980; Jiménez, 1995). However, being larger in size, the eagles may be at a competitive

300 advantage, ultimately limiting the abundance of the smaller hawk species. The lower abundance

301 of other raptors where BCB eagles abundance is high, could be influenced by intraguild

302 predation (Sergio \& Hiraldo, 2008; Treinys et al., 2011). In fact, there is evidence of predation of

303 some of these species (e.g., M. chimango, F. sparverius) by the BCB eagles (Hiraldo et al., 1995)

304 and also frequent agonistic interactions with other raptors (mostly with G. polyosoma; Jiménez \& 305 Jaksić, 1989). 
$\mathrm{BCB}$ eagles spaced their territories more closely than expected given their body size

308 showing that there is not only simply a spatial aggregation of foraging individuals, but of

309 breeding territories. From our meta-regression C. pomarina was the only other raptor to show

310 decreased territory size, spacing more closely together than expected. The most influential study

311 to examine $\mathrm{NND}_{\text {avg }}$ described a case study that found enhanced breeding parameters were

312 associated with synchronicity and super abundance of their main prey (Mycrotus spp.; Treinys,

313 Bergmanis \& Väli, 2017); thus supporting the resource availability-territory size hypothesis. On

314 the other hand, the Golden eagle (A. chrysaetos) was the only species to have a greater NND

315 than expected. This could be related to their huge size variability. The species average weight is

316 about $4600 \mathrm{~g}$, however there are individuals that exceed $6700 \mathrm{~g}$ (Ferguson-Lees \& Christie,

317 2001), representing a much greater energetic constraint. However this species also responds to

318 the presence and abundances of their main prey (Clouet et al., 2017), where the presence of

319 rabbits is enough to reduce their NND form 12.9 to $8.6 \mathrm{~km}$.

320

In Patagonia the NND for the BCB eagle was smaller than expected for its body size and

322 in comparison to that of the two closest species in weight, the lighter T. ecaudatus and A. rapax.

323 Given that the latter species and A. heliaca all fall into the expected values we are confident that

324 the difference is not due to any statistical construct on the meta-regression, but rather the

325 biological mechanism we are testing. Moreover, our own field NND estimates were slightly

326 higher than those found for this species in the same region 20 years ago (with a mean of $2522 \mathrm{~m}$,

327 Hiraldo et al., 1995 vs. 3760 in this study). This could be related to the fact that the abundances

328 of hare have showed a slight decline over the last two decades, therefore limiting the resources

329 for breeding eagles (Ignazi et al., submitted). 

assessed by this study, for example, the spatial arrangement of $\mathrm{BCB}$ eagles prior to hare introduction . Unfortunately studies on these matters have started when hares were already abundant and conspicuous participants of the ecosystem (Grigera \& Rapoport, 1983). Here we found that BCB eagles show lower NNDs than expected, at the same time that its main resource is in extremely high abundances. This suggests that large eagles may aggregate more closely under high resource abundances. make NND estimations in some cases impervious to food resource changes. For instance, previous research on $\mathrm{BCB}$ eagles showed that adults tend to favor nesting areas rather than rich resource patches (Bustamante et al., 1997). In this case, nest fidelity and the costs associated with the relocation and defense of a new territory could be masking the effect of a shortage in

food (Saggese et al., in press). Although our meta-regression between NND and body masses of predators allowed us to identify that $\mathrm{BCB}$ eagles are spacing their territories closer than expected, future research on breeding parameters and shifts in the eagles' diets are necessary to fully understand the relation between this predator and disparate abundances of its main prey 348 (Ignazi et al., submitted).

\section{Conclusions}

Overall, the enhanced population of a top predator caused by the presence of an exotic

352 prey could create important conservation issues for the invaded communities and the surrounding 
353

354

355

356

357

358

359

360

361

362

363

364

365

366

367

368

369

370

371

372

environments. A shift in the diet of a top predator to an alien species could reduce the per capita intake of native prey. However, as this exotic prey increases, the predator abundance could create apparent competition interactions (Holt, 1977; Oliver, Luque-Larena \& Lambin, 2009).

This is particularly concerning when considering that hare populations are already prone to great natural variations, and also used as game species in several regions (Flux \& Angermann, 1990; Wilson, Lacher Jr \& Mittermeier, 2016). Even if this is not the case, the sole change in spatial use by a predator could change the activity and distribution patterns of the prey, changing their landscape of fear (Willems \& Hill, 2009) or making native prey underperform (Lyly et al., 2015). Furthermore, within the same trophic level, high abundance of the largest species in the guild could lead to an increase in the intraguild predation (Sergio \& Hiraldo, 2008). All of these factors lead to an unbalanced structure of the invaded food web (Simberloff \& Von Holle, 1999; de Ruiter et al., 2005). Conservation biologists should therefore be cautious when planning invasive species management, in order to reduce further and sudden changes in the invaded communities (Myers et al., 2000).

\section{Acknowledgments}

We wish to dedicate this work to Mikel Larrea, a young and enthusiastic raptor researcher that left us way too soon. We thank the land managers of "El Cóndor", "San Ramón", "Rinconada" and Lonco Audulio Pailallef for permissions to work in their lands. We thank to Hannah Williams for comments on an early version of this manuscript. 
373

374

375

376

377

378

379

380

381

382

383

384

385

386

387

388

389

390

391

392

393

\section{References}

Aljetlawi AA, Sparrevik E, Leonardsson K. 2004. Prey-predator size-dependent functional response: derivation and rescaling to the real world. Journal of Animal Ecology 73:239252. DOI: $10.1111 / \mathrm{j} .0021-8790.2004 .00800 . x$.

Allhoff KT, Drossel B. 2016. Biodiversity and ecosystem functioning in evolving food webs. Philosophical Transactions of the Royal Society. B 371:20150281.

Amarasekare P. 2002. Interference competition and species coexistence. Proceedings of the Royal Society of London B: Biological Sciences 269:2541-2550.

Amarasekare P. 2003. Competitive coexistence in spatially structured environments: a synthesis. Ecology Letters 6:1109-1122.

Barbar F, Hiraldo F, Lambertucci SA. 2016. Medium-sized exotic prey create novel food webs: the case of predators and scavengers consuming lagomorphs. PeerJ 4:e2273. DOI: $10.7717 /$ peerj. 2273 .

Barbar F, Werenkraut V, Morales JM, Lambertucci SA. 2015. Emerging ecosystems change the spatial distribution of top carnivores even in poorly populated areas. PLOS ONE 10:e0118851. DOI: 10.1371/journal.pone.0118851.

Barnosky AD, Hadly EA, Bascompte J, Berlow EL, Brown JH, Fortelius M, Getz WM, Harte J, Hastings A, Marquet PA, Martinez ND, Mooers A, Roopnarine P, Vermeij G, Williams JW, Gillespie R, Kitzes J, Marshall C, Matzke N, Mindell DP, Revilla E, Smith AB. 2012. Approaching a state shift in Earth/'s biosphere. Nature 486:52-58. DOI: 10.1038/nature11018. 
394 Bates D, Maechler M, Bolker B, Walker S, Christensen RHB, Singmann H, Dai B, Grothendieck

395

396

397

398

399

400

401

402

403

404

405

406

407

408

409

410

411

412

413

414

415

G, Eigen C, Rcpp L. 2014. Package 'lme4.’ R Foundation for Statistical Computing, Vienna.

Bivand R, Lewin-Koh N, Pebesma E, Archer E, Baddeley A, Bearman N, Bibiko H-J, Brey S, Callahan J, Carrillo G, others 2017. Package 'maptools.': Tools for Reading and Handling Spatial Objects. R package version 0.9-2. https:/CRAN.Rproject.org/package $=$ maptools

Bivand R, Rundel C. 2014. rgeos: Interface to Geometry Engine-Open Source (GEOS). R Package Version 0.3-6. https:/CRAN.R-project.org/package=rgeos. Comprehensive $R$ Archive Network, Vienna, Austria.

Bonino N, Cossíos D, Menegheti J. 2010. Dispersal of the European hare, Lepus europaeus in South America. Folia Zoologica 59:9.

Brose U. 2010. Body-mass constraints on foraging behaviour determine population and foodweb dynamics. Functional Ecology 24:28-34. DOI: 10.1111/j.1365-2435.2009.01618.x.

Brose U, Jonsson T, Berlow EL, Warren P, Banasek-Richter C, Bersier L-F, Blanchard JL, Brey T, Carpenter SR, Blandenier M-FC. 2006. Consumer-resource body-size relationships in natural food webs. Ecology 87:2411-2417.

Bustamante J, Donázar JA, Hiraldo F, Ceballos O, Travaini A. 1997. Differential habitat selection by immature and adult Grey Eagle-buzzards Geranoaetus melanoleucus. Ibis 139:322-330.

Cabrera AL. 1976. Regiones fitogeográficas argentinas. Buenos Aires: Acme.. 85 pp. (Enciclopedia argentina de agricultura y jardinería ; Tomo 2 fasc. 1) 
416 Chase JM, Leibold MA. 2003. Ecological niches: linking classical and contemporary

417 approaches. University of Chicago Press. IL, USA

418 Clark PJ, Evans FC. 1954. Distance to nearest neighbor as a measure of spatial relationships in 419 populations. Ecology 35:445-453.

420 Clouet M, Gerard J-F, Goar J-L, Goulard M, González L, Rebours I, Faure C. 2017. Diet and 421 breeding performance of the Golden eagle Aquila chrysaetos at the eastern and western 422 423 extremities of the Pyrenees: an example of intra-population variability. Ardeola 64:347361.

Coronato AMJ, Coronato F, Mazzoni E, Vázquez M. 2008. The Physical Geography of Patagonia and Tierra del Fuego. In: Rabassa J ed. Developments in Quaternary Sciences. The Late Cenozoic of Patagonia and Tierra del Fuego. Elsevier, 13-55. DOI: 10.1016/S1571-0866(07)10003-8.

Damuth J. 1981. Population density and body size in mammals. Nature 290:699-700.

Damuth J. 2007. A macroevolutionary explanation for energy equivalence in the scaling of body

431

432 433 434 435 436 size and population density. The American Naturalist 169:621-631.

Ferguson-Lees J, Christie DA. 2001. Raptors of the world. Houghton Mifflin Harcourt.

Flux JE, Angermann R. 1990. The hares and jackrabbits. Rabbits, Hares and Pikas. Status survey and conservation action plan 4:61-94.

Galende GI, Trejo A. 2003. Depredación del águila mora (Geranoaetus melanoleucus) y el búho (Bubo magellanicus) sobre el chinchillón (Lagidium viscacia) en dos colonias del noroeste de Patagonia, Argentina. Mastozoología Neotropical 10:143-147. 
437 Griffin JN, De La Haye KL, Hawkins SJ, Thompson RC, Jenkins SR. 2008. Predator diversity 438 and ecosystem functioning: density modifies the effect of resource partitioning. Ecology 89:298-305.

440

441

442

443

444

445

446

447

448

449

450

451

452

453

454

455

456

457

458

459

Grigera DE, Rapoport EH. 1983. Status and distribution of the European hare in South America. Journal of Mammalogy 64:163-166.

Guisan A, Thuiller W. 2005. Predicting species distribution: offering more than simple habitat models. Ecology Letters 8:993-1009.

Guisan A, Zimmermann NE. 2000. Predictive habitat distribution models in ecology. Ecological Modelling 135:147-186.

Higgins J, Thompson SG. 2002. Quantifying heterogeneity in a meta-analysis. Statistics in medicine 21:1539-1558.

Hijmans RJ. 2016. Geosphere: Spherical trigonometry. $R$ package version 1.5-5.

Hiraldo F, Donázar JA, Bustamante J, Ceballos O, Travaini A, Funes M. 1995. Breeding biology of a grey eagle-buzzard population in Patagonia. Wilson Bulletin:675-685.

Holt RD. 1977. Predation, apparent competition, and the structure of prey communities. Theoretical Population Biology 12:197-229.

Hunter JE, Schmidt FL. 2000. Fixed effects vs. random effects meta-analysis models: Implications for cumulative research knowledge. International Journal of Selection and Assessment 8:275-292.

Ignazi GO. 2015. Ground Nesting by Black-chested Buzzard-Eagles (Geranoaetus melanoleucus). Journal of Raptor Research 49:101-103.

Iriarte JA, Franklin WL, Johnson WE. 1990. Diets of sympatric raptors in southern Chile. Journal of Raptor Research 24:41-46. 
460 Jiménez JE. 1995. Historia natural del Aguilucho Buteo polyosoma: una revisión. Hornero $461 \quad 14: 001-008$.

462 Jiménez JE, Jaksić FM. 1989. Behavioral ecology of grey eagle-buzzards, Geranoaetus 463 melanoleucus, in central Chile. Condor 91:913-921.

464 Lambertucci SA, Ruggiero A. 2016. Cliff outcrops used as condor communal roosts are local 465 hotspots of occupancy and intense use by other bird species. Biological Conservation $466 \quad 200: 8-16$.

467 Lambertucci SA, Speziale KL, Rogers TE, Morales JM. 2009. How do roads affect the habitat $468 \quad$ use of an assemblage of scavenging raptors? Biodiversity and Conservation 18:20634692074.

470 López CM, Grande JM, Orozco-Valor PM. 2017. Unusual Concentration of Black-chested 471 Buzzard-Eagles in Central Argentina. Journal of Raptor Research 51:489-491.

472 Loreau M, Hector A. 2001. Partitioning selection and complementarity in biodiversity 473 experiments. Nature 412:72-76. DOI: 10.1038/35083573.

Lyly MS, Villers A, Koivisto E, Helle P, Ollila T, Korpimäki E. 2015. Avian top predator and 475 the landscape of fear: responses of mammalian mesopredators to risk imposed by the golden eagle. Ecology and Evolution 5:503-514. DOI: 10.1002/ece3.1370.

MacLean SF, Seastedt TR. 1979. Avian Territoriality: Sufficient Resources or Interference Competition. American Naturalist 114:308-312. DOI: 10.1086/283478.

Martin TE.1996. Fitness costs of resource overlap among coexisting bird species. Nature 480 $380: 338-340$.

McDonald RA. 2002. Resource partitioning among British and Irish mustelids. Journal of 482 Animal Ecology 71:185-200. 
483 McDonald T, Nielson R, Carlisle J. 2015. Rdistance: Distance Sampling Analyses.

484 https://CRAN.R-project.org/package=Rdistance

485

486

487

488

489

490

491

492

493

494

495

496

497

498

499

500

501

502

503

504

505

McKinney ML, Lockwood JL. 1999. Biotic homogenization: a few winners replacing many losers in the next mass extinction. Trends in Ecology \& Evolution 14:450-453.

Monserrat AL, Funes MC, Novaro AJ. 2005. Dietary response of three raptor species to an introduced prey in Patagonia. Revista Chilena de Historia Natural 78:129-143.

Myers JH, Simberloff D, Kuris AM, Carey JR. 2000. Eradication revisited: dealing with exotic species. Trends in Ecology \& Evolution 15:316-320. DOI: 10.1016/S0169$5347(00) 01914-5$.

Newsome TM, Dellinger JA, Pavey CR, Ripple WJ, Shores CR, Wirsing AJ, Dickman CR. 2015. The ecological effects of providing resource subsidies to predators. Global Ecology and Biogeography 24:1-11. DOI: 10.1111/geb.12236.

Newton I. 2010. Population ecology of raptors. Poyser monographs 18. 432 p. A\&C Black. ISBN-13: 9781408138533

Oksanen J. 2017. Vegan: an introduction to ordination. Community Ecology Package. R package version 2.4-3. https://CRAN.R-project.org/package=vegan

Oliver M, Luque-Larena JJ, Lambin X. 2009. Do rabbits eat voles? Apparent competition, habitat heterogeneity and large-scale coexistence under mink predation. Ecology Letters 12:1201-1209.

Palmqvist P, Palomo LJ, Pérez-Claros JA, Vargas JM. 1996. Relación entre peso corporal, tamano del territorio, tamaño de puesta y tiempo de desarrollo en algunas rapaces del Paleártico occidental. Boletín de la Real Sociedad Espanola de Historia Natural 92:4754. 
506 Paruelo JM, Beltran A, Jobbagy E, Sala OE, Golluscio RA. 1998. The climate of Patagonia:

507 general patterns and controls on biotic. Ecología Austral 8:85-101.

508 Pavez EF. 2001. Biología reproductiva del águila Geranoaetus melanoleucus (Aves:

509 Accipitridae) en Chile central. Revista Chilena de Historia Natural 74:687-697.

510 Pedrini P, Sergio F. 2001. Golden Eagle Aquila chrysaetos density and productivity in relation to 511 land abandonment and forest expansion in the Alps. Bird Study 48:194-199.

512 Peery MZ. 2000. Factors affecting interspecies variation in home-range size of raptors. Auk 117:511-517.

514 Peters RH. 1986. The ecological implications of body size. Cambridge University Press.

515 R Development Core Team 2012. R: A language and environment for statistical computing.

516 Rodríguez JP. 2001. Exotic species introductions into South America: an underestimated threat?

517 Biodiversity \& Conservation 10:1983-1996. DOI: 10.1023/A:1013151722557.

518 de Ruiter PC, Wolters V, Moore JC, Winemiller KO. 2005. Food web ecology: playing Jenga $519 \quad$ and beyond. Science 309:68-71.

520 Saggese MD, De Lucca ER. 2001. Biología reproductiva del Aguila Mora (Geranoaetus

521 melanoleucus) en la Patagonia sur, Argentina. Hornero 16:77-84.

522 Saggese MD, De Lucca ER, Quaglia AIE, Nelson RW, Davis HE. In Press. Long-term nosting territiory occupancy in Black-chested Buzzard-eagles (Geranoaetus melanoleucus) in

Schlatter RP, Yáñez JL, Jaksić FM. 1980. Food-niche relationships between Chilean Eagles and 526 Red-backed Buzzards in central Chile. Auk 97:897-898. $10.2307 / 1933567$. 
529 Schoener TW. 1983. Simple models of optimal feeding-territory size: a reconciliation. American $530 \quad$ Naturalist 121:608-629.

531 Sergio F, Hiraldo F. 2008. Intraguild predation in raptor assemblages: a review. Ibis 150:132$532 \quad 145$.

533 Simberloff D, Martin J-L, Genovesi P, Maris V, Wardle DA, Aronson J, Courchamp F, Galil B, 534 García-Berthou E, Pascal M, others 2013. Impacts of biological invasions: what's what 535 and the way forward. Trends in Ecology \& Evolution 28:58-66.

536 Simberloff D, Von Holle B. 1999. Positive interactions of nonindigenous species: invasional 537 meltdown? Biological invasions 1:21-32.

538 Sonerud GA. 1992. Functional responses of birds of prey: biases due to the load-size effect in 539 central place foragers. Oikos:223-232.

540 Tilman D. 1999. The ecological consequences of changes in biodiversity: a search for general $541 \quad$ principles. Ecology 80:1455-1474.

542 Travaini A, Donazar JA, Rodriguez A, Bustamante J, Delibes M, Hiraldo F, Ceballos O, Funes M. 1994. Nest-site characteristics of four raptor species in the Argentinian Patagonia. Wilson Bulletin 106:753-757.

545 Travaini A, Donázar JA, Rodríguez A, Ceballos O, Funes M, Delibes M, Hiraldo F. 1998. Use of

$546 \quad$ European hare (Lepus europaeus) carcasses by an avian scavenging assemblage in 547 Patagonia. Journal of Zoology 246:175-181.

548 Travaini A, Santillán MA, Zapata SC. 2012. Diet of the Red-backed Hawk (Buteo polyosoma) in 549 two environmentally contrasting areas of Patagonia. Studies on Neotropical Fauna and Environment 47:25-32. DOI: 10.1080/01650521.2011.649948. 
551 Treinys R, Bergmanis U, Väli Ü. 2017. Strong territoriality and weak density-dependent

552 reproduction in Lesser Spotted Eagles Clanga pomarina. Ibis 159:343-351.

553 Treinys R, Dementavičius D, Mozgeris G, Skuja S, Rumbutis S, Stončius D. 2011. Coexistence

554 of protected avian predators: does a recovering population of White-tailed Eagle threaten

555 to exclude other avian predators? European Journal of Wildlife Research 57:1165-1174.

556 DOI: $10.1007 / \mathrm{s} 10344-011-0529-7$.

557 Trejo A, Kun M, Seijas S. 2006. Dieta del Águila Mora (Geranoaetus melanoleucus) en una 558 transecta oeste-este en el ecotono norpatagónico. Hornero 21:31-36.

559 Viechtbauer W. 2010. Conducting meta-analyses in R with the metafor package. Journal of $560 \quad$ Statistical Software 36:1-48.

561 Vitousek PM. 1990. Biological invasions and ecosystem processes: towards an integration of 562 population biology and ecosystem studies. Oikos 57:7-13.

563 Vitousek PM, D’antonio CM, Loope LL, Rejmanek M, Westbrooks R. 1997. Introduced species: a significant component of human-caused global change. New Zealand Journal of Ecology:1-16.

White EP, Ernest SM, Kerkhoff AJ, Enquist BJ. 2007. Relationships between body size and abundance in ecology. Trends in ecology \& evolution 22:323-330.

Willems EP, Hill RA. 2009. Predator-specific landscapes of fear and resource distribution: effects on spatial range use. Ecology 90:546-555.

Wilson DE, Lacher Jr TE, Mittermeier RA. 2016. Handbook of the Mammals of the World. Vol. 
572 Zanón Martínez JI, Travaini A, Zapata S, Procopio D, Santillán MÁ. 2012. The ecological role

573 of native and introduced species in the diet of the puma Puma concolor in southern

$574 \quad$ Patagonia. Oryx 46:106-111. 


\section{Figure 1}

Map of the study area in the northwestern Patagonia Argentina.

The smaller dotted rectangle corresponds to the area where we conducted raptor and hare surveys. The roads used to perform the surveys are highlighted in green and each transect indicated with a numbered black circle. Red squares are the two regions where we actively searched for BCB eagle nests.

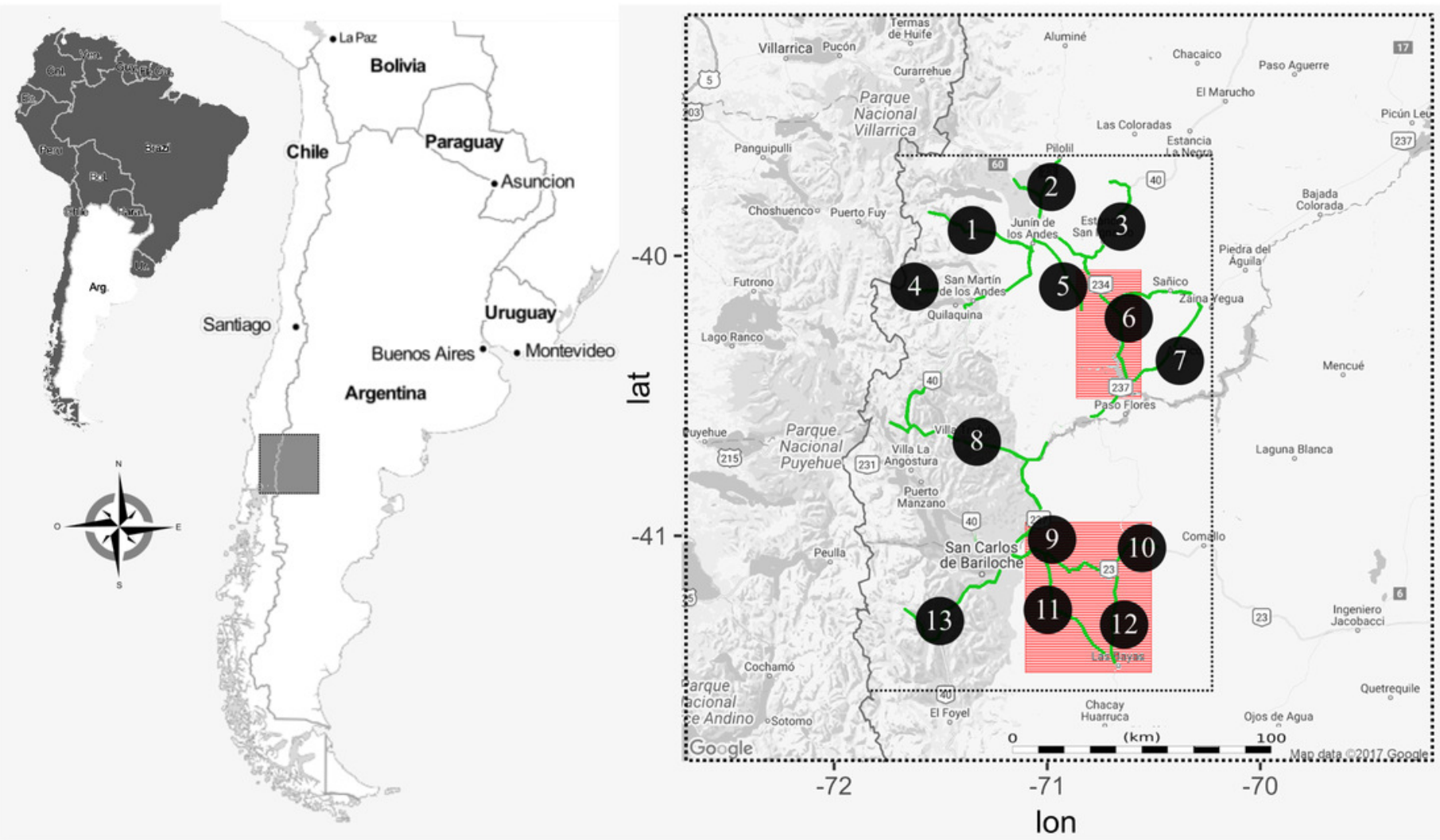


Figure 2

First two ordination axes form the correspondence analysis relating the abundances of the 5 raptor species and the abundances of European hare.

Distances between text labels represent the association among abundances of species by site. Shorter distances mean a more closely association between two species. Percentages show the total inertia explained by each axis.

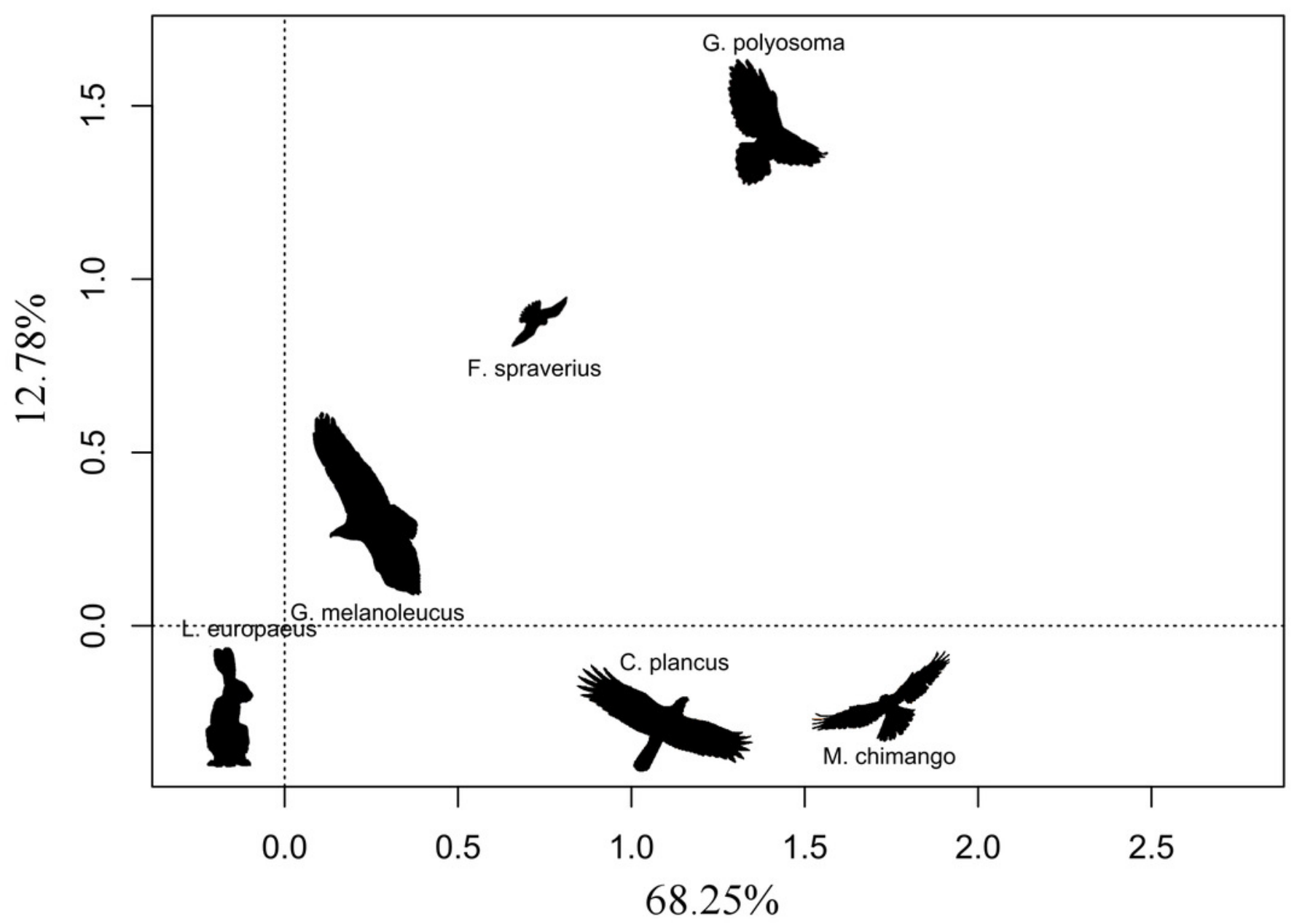


Figure 3

Meta-regression of the Nearest Neighbor Distance $\left(\mathrm{NND}_{\text {avg }}\right.$ ) for each Accipitridae raptor species in relation with their average weight.

Black diamonds are the model estimate (with a 95\% Cl) for each species. NND avg (with a 95\% $\mathrm{Cl}$ ) calculated from the measures extracted from each study are represented in squares. Highlighted in red are species which NND $_{\text {avg }}$ differed from the estimate.

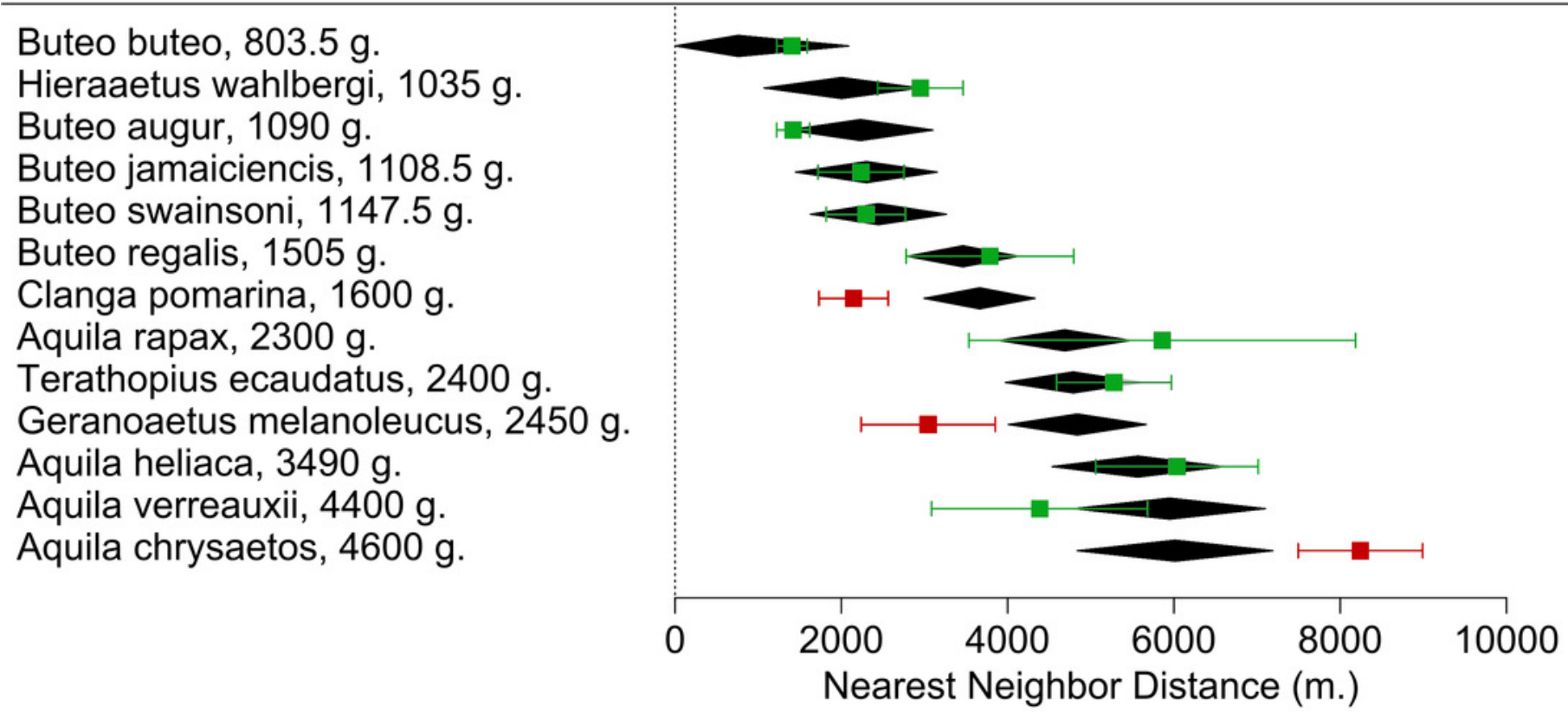

